\title{
A Cognitive Approach to Medieval Mode: Evidence for an Historical Antecedent to the Major/Minor System
}

\author{
DAVID HURON \\ Ohio State University \\ JOSHUA VELTMAN \\ Union University
}

\begin{abstract}
A random sample of 98 Gregorian chants was used to assemble "mode profiles"- pitch-class distributions for each of eight medieval modes in the manner of Krumhansl's and Kessler's (1982) key profiles. These profiles are shown to be useful in predicting the conventional modal designation for individual chants. An analysis of the eight mode profiles suggests that modes 3, 5 and 8 (Phrygian, Lydian and Hypomixolydian) are highly similar and can be distinguished from a more heterogeneous group consisting of the remaining modes. A cluster analysis of profiles for individual chants gives further evidence that these three modes form a supramodal category. The results are shown to be consistent with a theory of mode offered by the 11th-century writer, Johannes Cotto, who proposed that the tenor pitch is important in classifying modes. It is suggested that an observed polarization of the eight modes into two broad groups may have provided a cognitive kernel that facilitated the emergence of the major/minor system in the 17 th century.
\end{abstract}

Submitted 2005 July 1; accepted 2005 July 8.

KEYWORDS: mode, chant, tonality, cluster analysis, multidimensional scaling

THE subject of mode is among the most venerable topics in historical music scholarship. At the same time, the subject of tonality has proved to be one of the most active areas of research in the field of music perception and cognition. In this study, we will endeavor to link together these disparate areas of scholarship and apply a cognitively inspired approach to the study of mode. More specifically, we propose to apply the principles of structural tonality to an analysis of the interrelationships among the modes of the medieval eight-fold system.

Readers will likely be better versed in one or the other of these scholarly fields, so our study will begin by providing summary background information concerning modal theory and structural tonality. From this background we will formulate our principal hypothesis, assemble a test sample of music, and conduct a number of statistical analyses inspired by research in structural tonality. To anticipate our results, our analyses will suggest that some modes resemble each other in ways that music psychologists consider cognitively important.

At the outset it is important to understand that we will not make any claims about how medieval listeners perceived the various modes. Moreover, the research reported here relies on a number of assumptions, any one of which may render the approach misguided. Nevertheless, in applying experimentally established principles in music perception and cognition, it is possible to infer aspects of modal organization that may have been sources of perceptual ambiguity for medieval listeners. 


\section{THEORETICAL BACKGROUND}

\section{Modal Theory}

Historically, the concept of mode has provided a significant vehicle for theorizing about pitch-related organization in music. Modal theory has a long and complex history that ranges from the ancient Greeks to modern times. The modal theory of the Middle Ages that this article draws upon has been the subject of extensive research (Apel 1958; Atkinson 1982, 1989, 1995; Auda 1979; Curtis 1992; Gombosi 1938-40; Hucke 1974; Maitre 1997; Markovits 1977; Potiron 1953; Powers 1992; Powers/Wiering 2001; Schlager 1985, and others).[1] In particular, this article makes use of concepts of mode as they have been applied to the so-called Gregorian chant tradition, first synthesized by theorists in the 9th century and developed by other theorists over the ensuing few centuries. In the Latin West, theoretical ideas concerning mode were initially borrowed from Byzantium and ancient Greece. Around the 9th century, these ideas were imposed on an existing body of chants that had developed over the prior several centuries. The resulting tension between theory and practice gradually diminished as each exerted influence on the other. However, the repertoire remained more open-ended and heterogeneous in terms of melodic organization than the closed eight-mode system (discussed below) would suggest.

In the classic eight-mode system of the Middle Ages ca. 11th century, the two most important features for the modal classification of a chant are the final note (finalis) and the range (ambitus). Four different final notes (D, E, F and G) combine with two ambitus categories (authentic and plagal) to create eight modes. In authentic modes, the ambitus spans an octave that begins on the final; in plagal modes, the ambitus spans an octave that beings a fourth below the final. The resulting eight modes are commonly designated using either a system of names inspired by Greek nomenclature, or a system of numbers, as shown in Table 1.

\begin{tabular}{|cc|c|cc|}
\hline & Mode & Final & \multicolumn{2}{|c|}{ Ambitus } \\
\hline Number & Name & & category & range \\
\hline 1 & Dorian & D & authentic & D-d \\
2 & Hypodorian & D & plagal & A-a \\
3 & Phrygian & E & authentic & E-e \\
4 & Hypophrygian & E & plagal & B-b \\
5 & Lydian & F & authentic & F-f \\
6 & Hypolydian & F & plagal & C-c \\
7 & Mixolydian & G & authentic & G-g \\
8 & Hypomixolydian & G & plagal & D-d \\
\hline
\end{tabular}

Table 1. Characteristic features most commonly used in the classification of medieval modes.

In addition to the two principal factors of finalis and ambitus, a number of additional features were also commonly considered by theorists of the time when classifying the mode of a given chant. These include the first notes of phrases (initials), especially the first note of the whole chant, and the last notes of phrases (medial cadences), excluding the final note.

A certain feature derived from the chant sub-genre known as psalmody (the singing of psalm verses according to melodic formulas called psalm tones) was also grafted onto the overall conception of mode. When singing according to psalm tones, the majority of text is sung on a single "reciting tone" which is also called the "tenor." The eight different psalm tones each had a specific pitch designated as the tenor, though some psalm tones shared a common tenor (see Table 2). The pitch of any given psalm-tone tenor was also thought to be significant for characterizing the mode that corresponded to the particular psalm tone (e.g., mode 1 corresponds to the first psalm tone); thus psalmodic chant exerted influence on theories concerning non-psalmodic chant.[2] 


\begin{tabular}{|r|ccc|ccc|c|c|}
\hline Psalm tone: & 1 & 4 & 6 & 3 & 5 & 8 & 2 & 7 \\
Tenors: & A & A & A & C & C & C & F & D \\
Finals: & D & E & F & F & E & G & D & G \\
Mode: & 1 & 4 & 6 & 3 & 5 & 8 & 2 & 7 \\
\hline
\end{tabular}

Table 2. Relationships among modes, finals, and psalm-tone tenors / reciting tones according to Johannes Cotto (late 11th century).

The role of the tenor was advocated notably by the 11th-century theorist Johannes Cotto (Cotto, n.d.). Table 2 identifies the relationships among modes, finals, and psalm-tone tenors as described by Cotto. The table divisions highlight the four mode-related groups that arise when classification is based on tenors alone.

Apart from the functions of individual pitches that have been discussed so far, modal theory also identified certain melodic archetypes (characteristic melodic contours) that were considered to be fundamental to the identity of the various modes (Curtis, 1992; Powers/Wiering, 2000). Additional facets of modal theory have also been identified by various modern scholars (see Powers/Wiering, 2000). However, while acknowledging the complexity of modal theory as it developed over time, this study will apply a well-known approach in modern music perception in an attempt to gain further insight into the nature of modal organization.

\section{Structural Tonality}

Independently of modal theory, research in music perception over the past twenty years has established some simple principles that appear to underlie how listeners experience the interrelated phenomena of scale, mode, key, and tonality. The so-called "structural" view of tonality originates in the work of Carol Krumhansl (Krumhansl, 1990). What musicians call the tonic pitch has a number of subjective and objective correlates. Subjectively, the tonic is typically perceived by listeners as sounding "most stable" or "most complete." Objectively, the tonic pitch is among the most frequently occurring pitch class in a passage exhibiting uniform tonality. Other scale and non-scale tones typically exhibit a consistent hierarchy of occurrence, so even if the tonic is not the most common pitch in a given passage, the other tones typically exhibit a predictable rank ordering. In addition, the tonic is more likely to terminate phrases and is more likely to end a musical work.

This structural view of tonality is known to be only a partial explanation. Tonality perception is also known to be influenced by pitch proximity (Oram \& Cuddy, 1995), metrical stress (Hébert, Peretz \& Gagnon, 1995), and the aggregate duration of tones (Lantz \& Cuddy, 1998; Cuddy, 1997). In addition, the purely structural view commonly fails to account for tonality implications arising from differences of pitch order. West and Fryer (1990), for example, showed that randomizing the order of pitches tends to homogenize the responses of listeners to different probe tones. More pointedly, Brown (1988) showed that pitch order can have a significant influence on tonality perception. Butler (1999) has suggested the operation of at least two sorts of schemes, one time-independent and one time-dependent. This view is reinforced by the results of Huron and Parncutt (1993), who showed that the performance of the KrumhanslSchmuckler key-finding algorithm (see Krumhansl, 1990) in predicting order effects could be significantly improved by taking into account the short-term decay of pitch memory (so-called echoic memory decay). However, Huron and Parncutt found that the improved model was still unable to account for systematic ordering phenomena evident in Brown's experimental data. That is, the influence of pitch ordering on tonality perception cannot be attributed solely to the decay of pitch memory.

These caveats notwithstanding, a wealth of experimental data shows that the simple frequency of occurrence of various pitch classes plays a significant role in tonality perception (Cuddy, 1993; Cuddy \& Baderstscher, 1987; Lamont, 1998; Oram \& Cuddy, 1995). Indeed, Aarden (2003) has shown that the cognitive schemas related to the distribution of pitch classes are even more closely related to the frequency of events than was formerly supposed by the advocates of structural tonality. Perhaps more importantly, evidence consistent with structural tonality has been observed in non-Western musical practices such as Indian classical music (Castellano, Bharucha \& Krumhansl, 1984), Balinese music (Kessler, Hansen \& Shepard, 1984), and Korean p'iri music (Nam, 1998). In the case of the traditional Korean p'iri music, for example, 
the most frequently occurring pitch also tends to terminate breath-delimited phrases, and also coincides with the pitch identified by Korean musicians as the central pitch of the scale. Moreover, these pitches change systematically with respect to different Korean modes, and even with transposed pitch sets. The fact that structural tonality factors are readily observed in different cultures suggests that the approach has the potential to inform us about earlier periods in Western music history, such as in the modal system characteristic of the European Middle Ages.

\section{ANALYSIS}

\section{Applying Structural Tonality to Modal Theory}

As noted above, the goal of this study is to apply the principles of structural tonality to an analysis of medieval modes. Of course we do not have access to medieval listeners and so have no opportunity to collect any pertinent perceptual data. Ideally, we would carry out experiments on (say) 11th-century listeners using the Shepard probe-tone method to determine whether mode-defining contexts evoke a unique tonal schema for each mode. At face value, contemporaneous theory implies that medieval music was apprehended according to a system of eight modes. We have no way to determine whether typical listeners perceptually distinguished all eight modes, some smaller number of modes, or even a larger number of modes. However, if the principles of structural tonality also pertain to the perception of music in the Middle Ages, then we ought to see evidence consistent with various modal schemas. This evidence can be sought from notated music in the general distribution of pitch classes, and in the distributions of phrase-terminating pitches. In short, the goal of this study is to determine whether the principles of structural tonality can inform us regarding the classification of medieval modes.

If the structural tonality model is pertinent in the case of mode, then we would expect works in the same mode to exhibit highly similar pitch-class profiles. Conversely, we would expect works in different modes to exhibit somewhat less similar pitch-class profiles. Our first order of business is to determine whether or not this is the case. That is, do works in mode 3, for example, exhibit similar pitch-class profiles? And if so, do they differ significantly from other modes such as mode 1? In other words, do works deemed to be in the same mode exhibit similar pitch-class distributions?

In testing this conjecture, we would predict that distributions for each mode would successfully distinguish works in that mode from works in other modes. In the case where two or more modes fail to be distinguished using this approach, we need to consider the possibility that two or more modes might belong to some "supramodal" category.

To answer this question, we carried out a study of the pitch-class distributions for a large sample of monophonic modal chants. A number of statistical techniques were used to characterize the similarity and dissimilarity among these chants and relate the results to conventional modal classifications. To anticipate our results, the evidence will suggest that:

1. Modal classification is indeed correlated with distributions related to pitch-class.

2. There is evidence suggesting the existence of a supramodal grouping of modes 3,5 and 8 (Phrygian, Lydian and Hypomixolydian). Apart from their respective final tones, the Phrygian and Hypomixolydian modes appear to be indistinguishable.

3. Without reference to the a priori modal designations, a cluster analysis will show that the tenor pitch appears to have a prominent role in distinguishing modes, an observation consistent with a theory of mode offered by the 11th-century theorist, Johannes Cotto.

4. The clustering of pitch-class profiles is suggestive of a nascent major/minor bifurcation that may have paved the way for the subsequent (17th-century) emergence of the modem major/minor system.

\section{Musical Sample}

In order to address the questions posed above we need a sample of appropriate music as well as a priori identification of the mode for each sampled work. A suitable source is provided by the Liber usualis (Benedictines of Solesmes, 1961), a compendium of over 2000 of the most frequently performed sacred medieval works. This collection was assembled by monastic scholars in the late 19th and early 20 th centu- 
a.
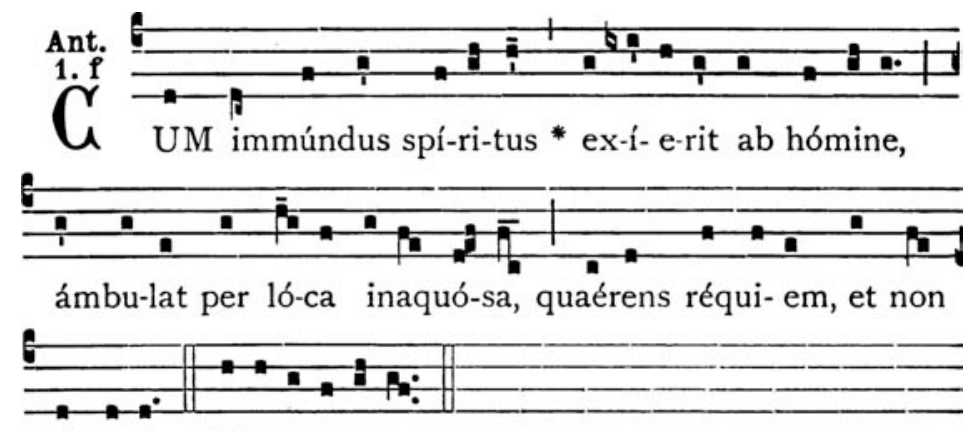

ínvenit. E u o u a e.
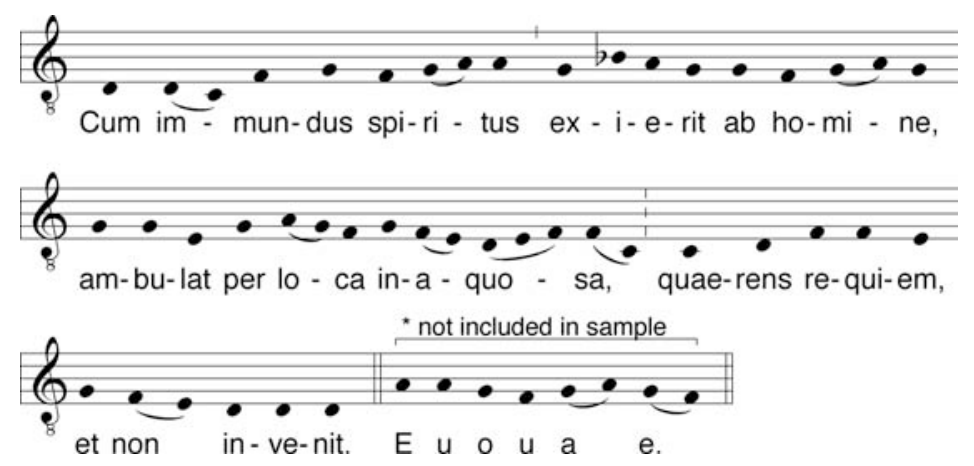

b.

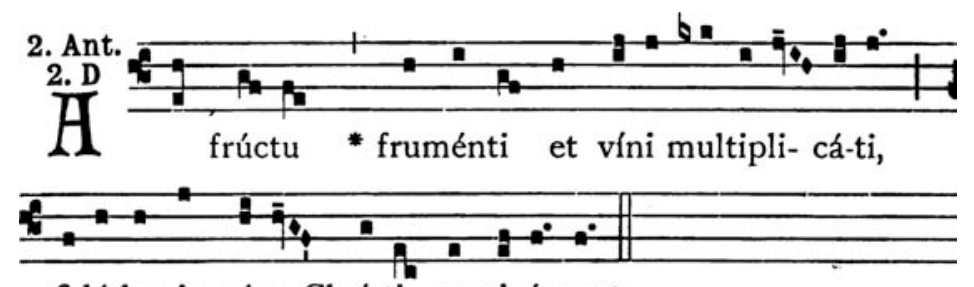

fidé-les in páce Chrísti requi-éscunt.
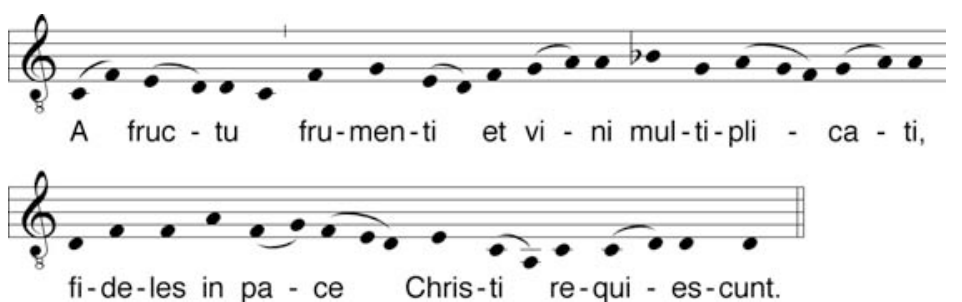

Figure 1. Two brief sample chants from the Liber usualis showing both the medieval square notation and a corresponding modern transcription. Note that duration and possible metric information are not indicated in the square notation. Figure la illustrates an authentic-mode chant that has been designated mode 1 (Dorian). The final tone is D. The theoretical ambitus allows for a span of one octave from $\mathrm{D}$ to $\mathrm{D}$. The actual range in this example is a minor seventh (from $\mathrm{C}$ to B-flat). This chant exhibits a seculorum amen tag at the end; these tags were omitted from the musical sample (see accompanying text). Figure 1b illustrates a plagal-mode chant designated mode 2 (Hypodorian). Again, the final tone is $\mathrm{D}$. The theoretical ambitus would span one octave from A to A; the actual range is a minor ninth, from A to B-flat. Divisiones identifying phrase boundaries are indicated by vertical strokes of varying lengths placed on the staff. 
-ries from many disparate manuscripts gathered from archives throughout western Europe. The Liber usualis represents a range of medieval musical traditions, styles, and historical eras.

Figure 1 displays two sample chants from the Liber usualis notated both in medieval square notation and in modem transcription. The chants shown are short and thus are not representative of the typical length. Note that duration and possible metric information are not indicated in the medieval notation. The first chant (Figure la) illustrates an authentic-mode chant that has been designated mode 1 (Dorian). The final tone is $\mathrm{D}$. The theoretical ambitus allows for a span of one octave from $\mathrm{D}$ to $\mathrm{D}$. The actual range in this example is a minor sixth, from D to B-flat. The second chant (Figure 1b) illustrates a plagal-mode chant designated mode 2 (Hypodorian). Although the theoretical final would normally be $\mathrm{D}$, this chant exhibits a final tone of $\mathrm{F}$. The theoretical ambitus would span one octave from $\mathrm{A}$ to $\mathrm{A}$; the actual range is once again a minor sixth, from D to B-flat.

It is worth noting that some modes occur more frequently than others. In the case of the Liber usualis for example, the most common modes-1 (Dorian) and 8 (Hypomixolydian) - occur roughly four times as often as the least common mode- 6 (Hypolydian). Figure 2 shows the frequency of occurrence of chants in each of the eight modes as indicated in the Liber usualis. Since the focus of our study is the relationship among modes, we need to ensure a commensurate sample size for each mode.

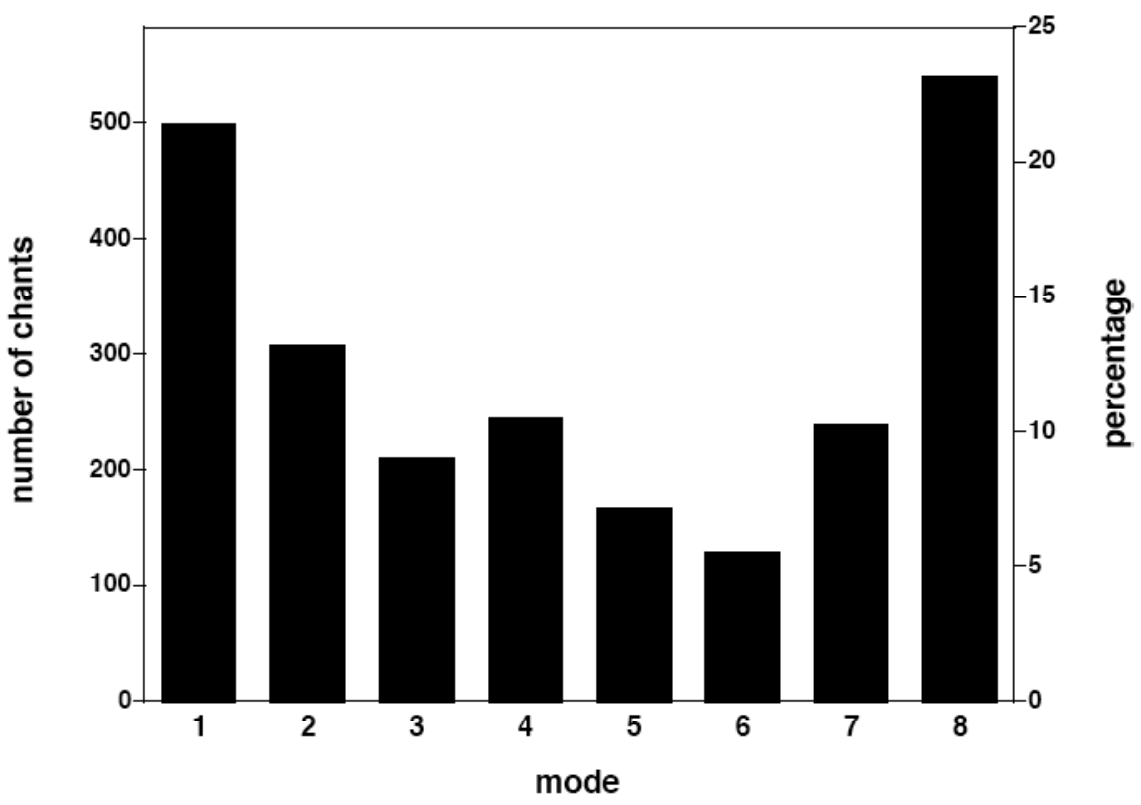

Figure 2. The frequency of occurrence of the various modes for the 2,333 chants in the Liber usualis. Modes 1 and 8 (Dorian and Hypomixolydian) are relatively common, whereas modes 5 and 6 (Lydian and Hypolydian) are comparatively rare. Mode classifications are those designated by the Solesmes monks.

In order to measure the relative success of classifying modes according to principles of structural tonality, we need an independent, a priori designation of each chant's mode. As noted above, ideally, we would have access to how experienced medieval listeners perceived the mode. A useful, though not infallible, approximation is to rely on mode identifications made by musicians or theorists practicing at the time. We elected to use the modal classifications indicated in the Liber usualis. These classifications were determined by late nineteenth- and early twentieth-century monastic scholars who edited the modem chant books (including the Liber usualis). These scholars determined modal classifications on the basis of indications, when given, in the manuscript sources themselves, and on the basis of analysis of chants in light of contemporaneous medieval theory. The editors of the modem chant books were given the responsibility of restoring the chant repertoire to its "authentic" historical state, insofar as possible. They are widely regarded by musicologists as having succeeded in this task, although their decisions are not immune to chal- 
lenge. In the case of mode, different manuscript sources sometimes give different modal designations for the same chant; in other instances, the melodic characteristics of a given chant may give rise to modal ambiguity that can legitimately be resolved in more than one way.[3] Notwithstanding these caveats, the Liber usualis provides a useful source for a priori modal designations.

\section{Sampled Chants}

Some chants in the Liber usualis appear in a transposed form. This is indicated by the presence of a single flat "signature." Such chants are typically transposed up a fourth from an original form and were retranscribed by medieval copyists for the sake of notational convenience. In order to avoid possible confusion in our presentation, we excluded transposed chants from our sample.

In sampling the various chants we established two further criteria. Each mode would be represented by a minimum of five chants, and since the individual chants differ in length, we would continue sampling chants for a given mode until a minimum of 1000 notes had been sampled. In total some 82 chants were randomly selected from the Liber usualis. Table 3 identifies the pertinent statistics for this sample.

Mode No.
1
2
3
4
5
6
7
8

$\begin{array}{cc}\text { Mode Name } & \text { \# of chants } \\ \text { Dorian } & 12 \\ \text { Hypodorian } & 9 \\ \text { Phrygian } & 10 \\ \text { Hypophrygian } & 14 \\ \text { Lydian } & 7 \\ \text { Hypolydian } & 6 \\ \text { Mixolydian } & 9 \\ \text { Hypomixolydian } & 9\end{array}$

Total \# of notes
1029
1119
1145
1297
1206
1032
1102
1193

Table 3: Summary Statistics for Sample of 82 Chants

Each chant was encoded using the Humdrum representation (Huron, 1999). The encoded information includes pitches and divisiones (phrase markings), as well as mode classifications. Text was not encoded. Each chant was subjected to a thorough error-checking procedure. We estimate that the pitch-class error rate for the complete sample is less than $0.1 \%$ (less than 1 error in 1000 notes) (see Huron, 1988).

A possible sampling confound that must be addressed relates to the presence of psalm passages in chants. In general, psalm passages center on a single "reciting tone," with occasional embellishments. Long psalm passages would have a tendency to markedly skew the distribution toward a single pitch. Two kinds of psalmody can be distinguished: simple and ornate. Ornate psalm passages are notated in the main section of the Liber usualis. By contrast, simple psalm passages are implied rather than explicitly notated, but can be reconstructed according to well-known conventions. Ornate psalm passages that occur in the context of a longer chant are clearly marked in the musical notation.

The inclusion of psalm passages raises issues related to sampling. On the one hand, one could argue that psalmody (both simple and ornate) should be included in the sample because such chants formed a part of the medieval listener's perceptual experience. On the other hand, the persistent repetition of a single pitch that is characteristic of psalmody would cause a significant reduction in the variance in pitch class distributions, and so make it more difficult to investigate differences between modes.

Given the high repetition rates for the reciting tone, we decided to omit such psalm passages. However, in sampling pieces in the various modes, we saw no reason to exclude a piece simply because it included a psalm passage. Therefore, as part of our sampling approach, the presence of these passages did not prevent a piece from participating in the sample, but the psalm passages themselves were omitted from the data.

A related sampling concern is the tag phrases that appear at the ends of many notated chants. These tag phrases include "Gloria Patri" and "E u o u a e" (short-hand for seculorum amen) which indicate the beginning and end of the Doxology (see Figure la). The Doxology is typically sung at the end of a 
psalm passage, and was also delivered in psalmodic style. Since the Doxology is essentially psalmodic in both function and style, and since the tags are not complete in themselves, we did not encode these tags in the sample.

\section{Mode Profiles}

For each mode, all of the notes from all of the chants were amalgamated and tallied. The result was eight pitch-class distributions, one for each mode. We will refer to these distributions henceforth as "mode profiles."[4]

\section{A Test of Modal Classification}

In order to determine whether mode profiles can be used to classify the mode of a chant, we randomly selected 16 additional chants as a test sample - two in each mode. To ensure sufficient data during the classification procedure, we selected only chants containing a minimum of 100 notes as part of the test sample.[5]

The use of pitch-class distributions to predict the key of a work was first proposed by Krumhansl. and Schmuckler (see Krumhans1, 1990). In the Krumhansl and Schmuckler method for key determination, the pitch-class distribution for a musical passage is compared with pre-existing profiles for the major and minor keys. The similarity between the key profile and the pitch-class distribution for a passage is measured using Pearson's correlation coefficient. Statistically, correlation is not the best approach for making such similarity comparisons.[6] A more reliable similarity measure is to calculate the Euclidean distance between the two vectors representing the proportions of the various pitch classes. For example, the distribution of pitch classes in a chant can be conceived as a point in an 8-dimensional space, where each dimension represents the proportion of notes for a given pitch class (C, D, E, F, G, A, B-flat, B).[7]

For each of the 16 chants in our test classification sample, we determined the distribution of pitch classes within the chant, and then measured the Euclidean distance to each of the 8 mode profiles derived from the earlier sample of 82 chants. The results are shown in Table 4 . The labels in the first column iden-

Test

\section{Chant}

$\begin{array}{cccc} & \mathbf{1} & \mathbf{2} & \mathbf{3} \\ 1 \mathrm{a} & * \mathbf{0 . 1 1 8 6} & 0.1189 & 0.1196 \\ \mathrm{1b} & * \mathbf{0 . 3 6 3 8} & 0.3641 & 0.3648 \\ \mathrm{2a} & 0.2953 & * \mathbf{0 . 2 9 4 7} & 0.2966 \\ \mathrm{2b} & 0.2631 & * \mathbf{0 . 2 6 2 5} & 0.2644 \\ \mathrm{3a} & 0.1813 & 0.1823 & * \mathbf{0 . 1 8 0 8} \\ \mathrm{3b} & 0.2415 & 0.2424 & * \mathbf{0 . 2 4 1 2} \\ \text { 4a } & 0.1574 & 0.158 & 0.1564 \\ \text { 4b } & 0.5137 & 0.5139 & 0.5127 \\ \text { 5a } & 0.2114 & 0.2115 & 0.2127 \\ \text { 5b } & 0.2065 & 0.2067 & 0.2080 \\ \text { 6a } & 0.1665 & 0.1660 & 0.1679 \\ \text { 6b } & 0.1531 & 0.1531 & 0.1546 \\ \text { 7a } & 0.1489 & 0.1490 & 0.1501 \\ \text { 7b } & 0.2922 & 0.2927 & 0.2934 \\ \text { 8a } & 0.3350 & 0.3348 & 0.3363 \\ \text { 8b } & 0.2281 & 0.2282 & 0.2293\end{array}$

\section{Classified Mode}

$\begin{array}{ccccc}\mathbf{4} & \mathbf{5} & \mathbf{6} & \mathbf{7} & \mathbf{8} \\ 0.1198 & 0.1201 & 0.1204 & 0.1191 & 0.1197 \\ 0.3648 & 0.3654 & 0.3653 & 0.3647 & 0.3647 \\ 0.2965 & 0.2958 & 0.2960 & 0.2951 & 0.2956 \\ 0.2642 & 0.2637 & 0.2638 & 0.263 & 0.2635 \\ 0.1816 & 0.1834 & 0.1836 & 0.1823 & 0.1827 \\ 0.2418 & 0.2433 & 0.2438 & 0.2423 & 0.2430 \\ * \mathbf{0 . 1 5 5 9} & 0.1595 & 0.1591 & 0.1586 & 0.1582 \\ * \mathbf{0 . 5 1 1 8} & 0.5155 & 0.5152 & 0.5146 & 0.5143 \\ 0.2128 & * \mathbf{0 . 2 0 9 8} & 0.2101 & 0.2104 & 0.2105 \\ 0.2081 & * \mathbf{0 . 2 0 5 5} & 0.2056 & 0.2058 & 0.2058 \\ 0.1671 & 0.1659 & * \mathbf{0 . 1 6 4 8} & 0.1664 & 0.1652 \\ 0.1545 & * \mathbf{0 . 1 5 1 8} & * \mathbf{0 . 1 5 1 8} & 0.1524 & 0.1523 \\ 0.1505 & 0.1483 & 0.1489 & * \mathbf{0 . 1 4 7 9} & 0.1490 \\ 0.2938 & 0.2923 & 0.2924 & * \mathbf{0 . 2 9 1 5} & 0.2918 \\ 0.3359 & 0.3350 & 0.3339 & 0.3347 & * \mathbf{0 . 3 3 3 2} \\ 0.2292 & 0.2280 & 0.2273 & 0.2276 & * \mathbf{0 . 2 2 6 5}\end{array}$

Table 4: Matrix of Euclidean Distances Between Aggregate Mode Profiles and Individual Pitch-class Distributions for Sixteen Test Chants 
-tify each of the 16 test pieces; the leading number indicates the a priori or "actual" mode, and the letters "a" and "b" distinguish the two test pieces used for each mode. The shortest Euclidean distance for each chant is indicated by an asterisk.

As can be seen, 15 of the 16 chants are correctly classified according to the a priori mode indications given in the Liber usualis. The sole ambivalent classification is evident in the second chant in mode 6 (Hypolydian) which showed an identical value for mode 5 (Lydian). At first glance, these results suggest that the use of pitch-class profiles for investigating modal organization is promising.

\section{Classification Under Transposition}

The above results overstate the within-mode pitch-class similarities, however, since the possibility of transposition was ignored. As in the modem major/minor system, modes might theoretically appear in different transpositions since the pitch system was relative rather than absolute. For example, although mode 1 (Dorian) is notated with the pitch D as the final, there is theoretically no obstacle to orienting the mode to some other pitch. The restricted medieval gamut (that is, no sharps or flats except B-flat) prevents chants from being notated with anything other than the conventional pitches, but there is nothing to prevent us in the present day from imagining an F\# Dorian, for instance.

A more thorough test of pitch-class classification would allow any mode to appear in any transposition. This transpositional procedure significantly increases the chances for misclassification. A significant technical problem arises when allowing transposition. In Table 4, we were able to employ pitch-class distributions using just 8 pitch-classes (C, D, E, F, G, A, B-flat, B). If we allow transpositions, other chromatic pitches are required and so the pitch-class vector must be expanded from 8 elements to 12 elements. The resulting Euclidean distances in the 12-dimensional space cannot be directly compared to the values given in Table 4.

Table 5 shows the results when all modes at all possible pitch levels are entertained. To avoid an unduly large table, only the shortest distance is shown for each test chant.

$\begin{array}{clc}\text { Test chant } & \text { Closest transposable mode } & \text { Euclidean distance } \\ \text { Ia } & \text { D Hypomixolydian } & 0.1185 \\ \text { 1b } & \text { B Hypophrygian } & 0.3637 \\ \text { 2a } & \text { F Lydian } & 0.2944 \\ \text { 2b } & \text { F Lydian } & 0.2623 \\ \text { 3a } & \text { D Hypomixolydian } & 0.1805 \\ \text { 3b } & \text { D Hypomixolydian } & 0.2409 \\ \text { 4a } & \text { B Hypophrygian } & \mathbf{0 . 1 5 5 9 *} \\ \text { 4b } & \text { B Hypophrygian } & \mathbf{0 . 5 1 1 8 *} \\ \text { 5a } & \text { D Hypomixolydian } & 0.2097 \\ \text { 5b } & \text { D Hypomixolydian } & 0.2055 \\ \text { 6a } & \text { C Hypolydian } & \mathbf{0 . 1 6 4 8 *} \\ \text { 6b } & \text { F Lydian } & 0.1518 \\ \text { 7a } & \text { G Mixolydian } & \mathbf{0 . 1 4 7 9 *} \\ \text { 7b } & \text { F\# Hypophrygian } & 0.2914 \\ \text { 8a } & \text { D Hypomixolydian } & \mathbf{0 . 3 3 3 2 *} \\ \text { 8b } & \text { D Hypomixolydian } & \mathbf{0 . 2 2 6 5 *}\end{array}$

Table 5. Minimum Euclidean Distances Between Transposed Aggregate Mode Profiles and Individual Pitch-class Distributions for Sixteen Test Chants

In this case, only 6 of the 16 test pieces were correctly classified (as indicated by asterisks). Nevertheless, this result remains statistically significant, due to the low probability of randomly assigning the correct classification. That is, a chant can ostensibly be classified as being one of 8 modes at 12 transposi- 
tion levels (96 possibilities). Therefore the chance of a random correct classification is roughly 1/96 rather than $1 / 8$.

While the above results fail to provide consistently accurate mode classifications, they remain consistent with the view that pitch-class distributions capture some aspect of modal distinctions. To say it another way, pitch-class distribution correlates with a true variable indicating mode.

Given this result, we amalgamated the original sample of 82 chants and the test sample of 16 chants to recalculate the eight mode profiles. This allows us to use all 98 chants in creating the various mode profiles. The resulting profiles are shown in Figures 3a-h.

a.

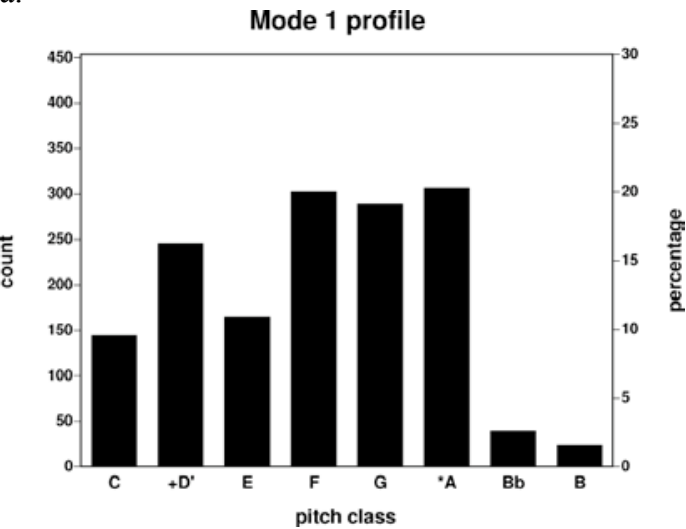

c.

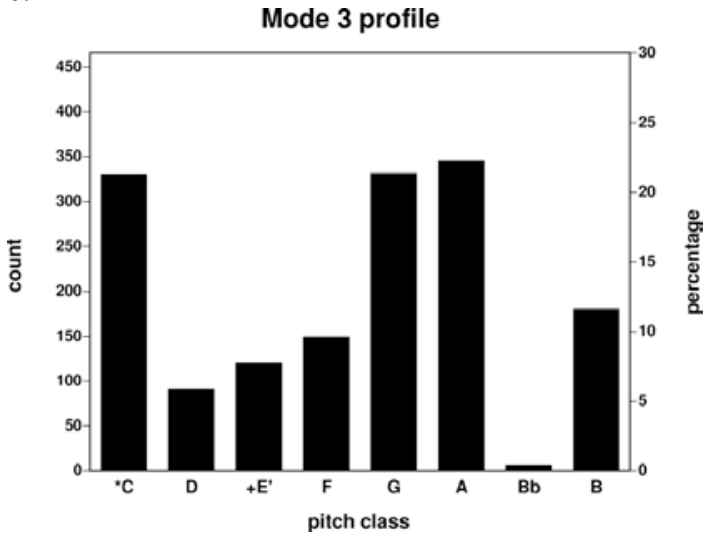

e.

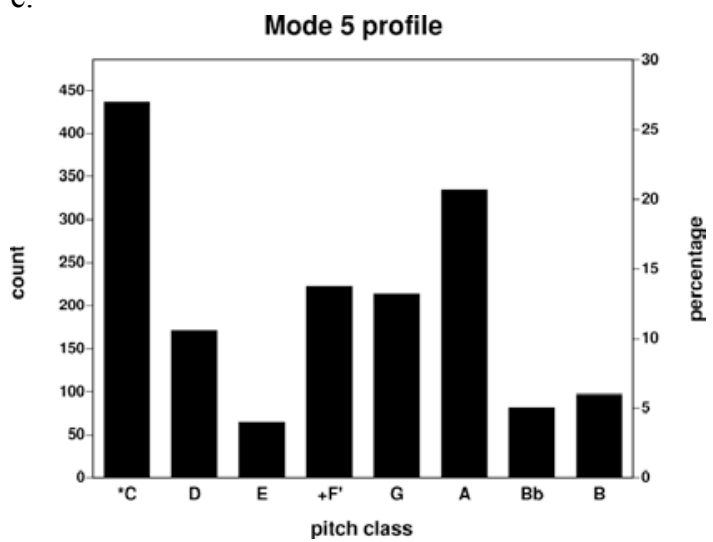

b.

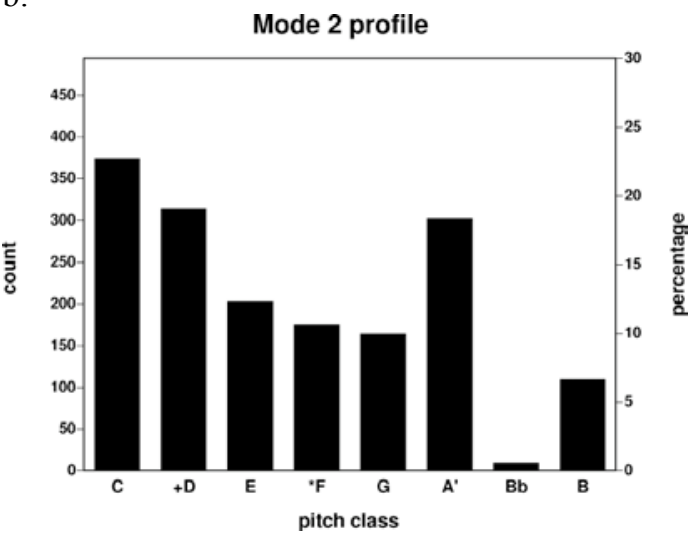

d.

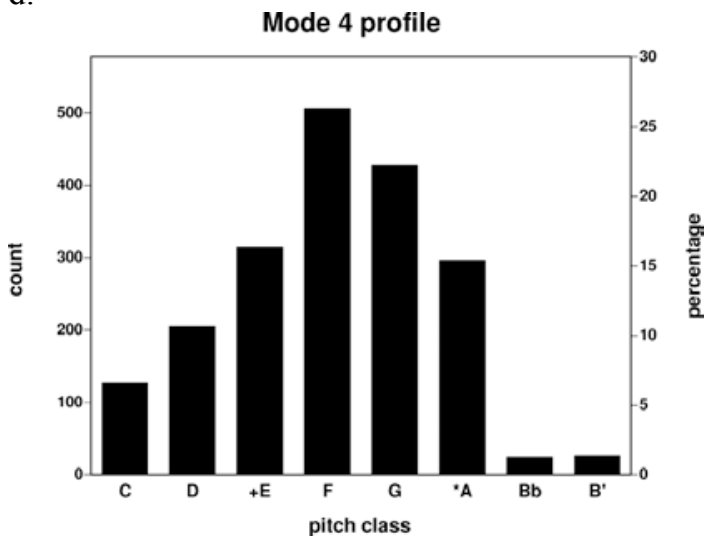

f.

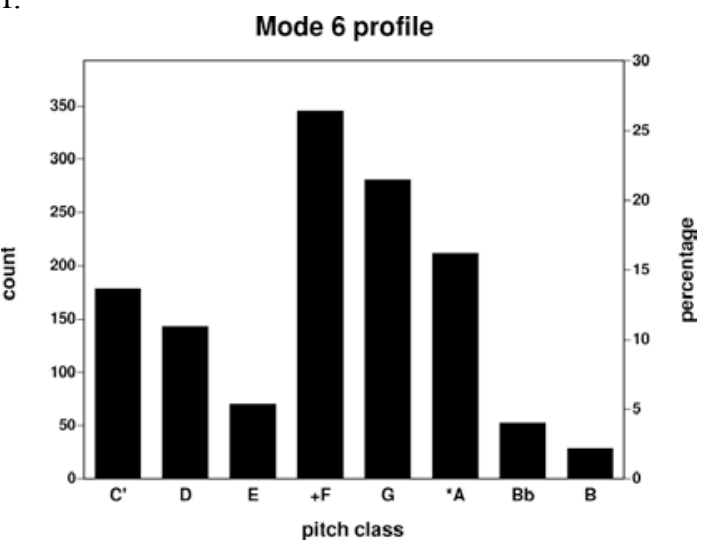

Figure 3 (continued on next page). 
g.

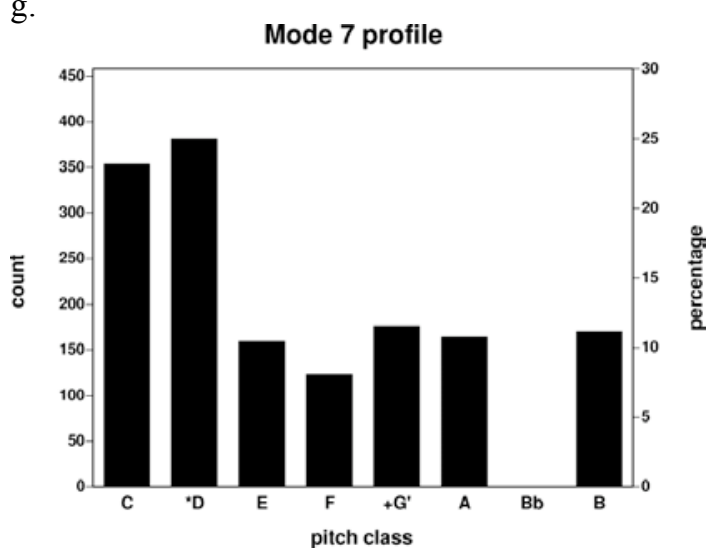

h.

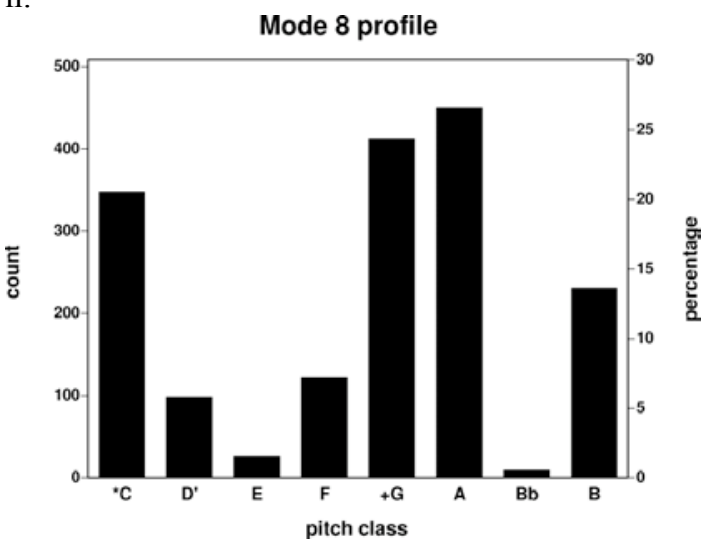

Figure 3 (continued from previous page). Mode profiles for the eight modes: Mode 1 (Dorian), Mode 2 (Hypodorian), Mode 3 (Phrygian), Mode 4 (Hypophrygian), Mode 5 (Lydian), Mode 6 (Hypolydian), Mode 7 (Mixolydian), Mode 8 (Hypomixolydian). Each graph shows the frequency of occurrence for each pitch class. Some modes exhibit similar distributions, notably modes 3 and 8. Graphs are based on a sample of 98 randomly selected chants from the Liber usualis. Asterisks indicate which tone is the tenor; a plus-sign indicates which tone is the final; a superscript indicates which pitch class marks the ambitus (highest and lowest pitches).

\section{Relationships Among Modes}

As can be seen in Figure 3, some of the mode profiles appear to be similar, such as modes 3 and 8 . Slightly less similar are modes 2 and 7 . This raises the question of whether there might exist supramodal groupings. One way to address this question is to measure the similarities between the aggregate mode profiles shown in Figure 3.

It is important to understand that some similarities and differences can be deceptive. For example, in the Krumhansl and Kessler key profiles, there are strong (though potentially misleading) similarities between the major and minor modes. Both the major and minor modes have high values for the tonic and dominant pitches and both have very low values for certain chromatic tones such as the raised tonic and the raised subdominant. As a consequence, the major and minor key profiles exhibit a significant positive correlation $(+0.51)$. Conversely, different transpositions can cause one to fail to recognize similarities. For example, the pitch-class distribution for works in $\mathrm{C}$ major and $\mathrm{D}$ major look dramatically different. Indeed, the profiles for $\mathrm{C}$ major and $\mathrm{C}$ minor look more similar than between $\mathrm{C}$ major and $\mathrm{D}$ major. Of course these observations are artifacts of thinking in in terms of absolute pitch rather than relative pitch.

In the case of Gregorian chant, there is every reason to suppose that relative pitch is more important than absolute pitch. The introduction to the Liber usualis explicitly states that the notated pitches are not to be construed as absolute and that singers should adapt the pitch height to a convenient vocal range.

All of this suggests that in comparing modes with one another we need to entertain the possibility that one mode might seem, from a perceptual point of view, to be a transposition of another, and that the similarities between two modes will become evident only at a particular transposition. As in the case of our classification study, when comparing the similarity of mode profiles we need to entertain all possible transpositions. To this end, we methodically transposed all eight aggregate mode profiles through all 12 pitch classes when measuring their similarities. This entailed 336 comparisons.

Of greatest interest are those modes and transposed modes which are nearest in the 12-dimensional Euclidean space. Table 6 shows only the nearest relationships from among all of the possible modal pairings. For example, when comparing mode 1 with mode 2, the closest Euclidean distance was evident when mode 2 was transposed up 5 semitones. Similarly, when comparing mode 1 with mode 3 , the closest Euclidean distance was evident when mode 3 remained untransposed. 


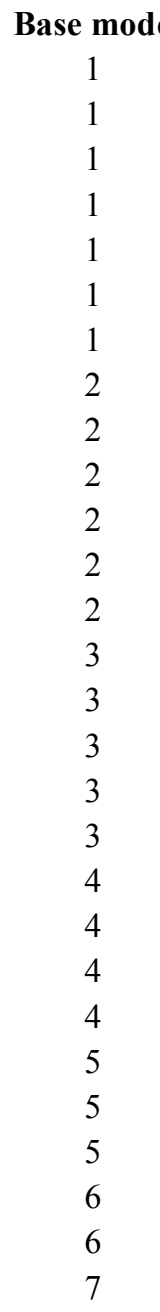

$\begin{array}{lc}\text { Comparison mode } & \text { Euclidean distance } \\ \text { mode } 2 \text { transposed }+5 \text { semits } & 0.145 \\ \text { mode } 3 \text { untransposed } & 0.225 \\ \text { mode } 4 \text { untransposed } & 0.133 \\ \text { mode } 5 \text { transposed }+5 \text { semits } & 0.237 \\ \text { mode } 6 \text { untransposed } & 0.106 \\ \text { mode } 7 \text { transposed }+5 \text { semits } & 0.151 \\ \text { mode } 8 \text { untransposed } & 0.260 \\ \text { mode } 3 \text { transposed }+5 \text { semits } & 0.184 \\ \text { mode } 4 \text { transposed }+7 \text { semits } & 0.211 \\ \text { mode } 5 \text { untransposed } & 0.160 \\ \text { mode } 6 \text { transposed }+7 \text { semits } & 0.128 \\ \text { mode } 7 \text { untransposed } & 0.111 \\ \text { mode } 8 \text { transposed }+5 \text { semits } & 0.206 \\ \text { mode } 4 \text { untransposed } & 0.289 \\ \text { mode } 5 \text { untransposed } & 0.129 \\ \text { mode } 6 \text { untransposed } & 0.208 \\ \text { mode } 7 \text { transposed }+7 \text { semits } & 0.221 \\ \text { mode } 8 \text { untransposed } & 0.089 \\ \text { mode } 5 \text { transposed }+7 \text { semits } & 0.253 \\ \text { mode } 6 \text { untransposed } & 0.155 \\ \text { mode } 7 \text { transposed }+5 \text { semits } & 0.142 \\ \text { mode } 8 \text { transposed }+10 \text { semits } & 0.309 \\ \text { mode } 6 \text { transposed }+7 \text { semits } & 0.212 \\ \text { mode } 7 \text { untransposed } & 0.200 \\ \text { mode } 8 \text { untransposed } 7 \text { transposed }+5 \text { semits } & 0.189 \\ \text { mode } 8 \text { transposed }+10 \text { semits } & 0.110 \\ \text { mode } 8 \text { transposed }+5 \text { semits } & 0.242 \\ & 0.210 \\ & \end{array}$

Table 6. Minimum Euclidean Distances Between Transposed Mode Profiles

$\begin{array}{clc}\text { Base mode } & \text { Comparison mode } & \text { Euclidean distance } \\ 3 & \text { mode } 8 \text { untransposed } & 0.089 \\ 1 & \text { mode } 6 \text { untransposed } & 0.106 \\ 6 & \text { mode } 7 \text { transposed }+5 \text { semits } & 0.110 \\ 2 & \text { mode } 7 \text { untransposed } & 0.111 \\ 2 & \text { mode } 6 \text { transposed }+7 \text { semits } & 0.128 \\ 3 & \text { mode } 5 \text { untransposed } & 0.129\end{array}$

Table 7. Closest Inter-Modal Distances

Table 7 recasts some of the information in Table 6, selecting only those modes which are nearest in the Euclidean space. The most similar mode profiles are those of untransposed modes 3 (Phrygian) and 8 (Hypomixolydian). The second most similar mode profiles are those of the untransposed modes 1 (Dorian) and 6 (Hypolydian). Inspection of the 10 most similar profiles leads to an apparent grouping of the eight modes into two groups. One group consists of modes, 3, 5, and 8. With somewhat less confidence, a second group might be identified consisting of modes 1, 2, 4, 6 and 7. More precisely, the second group consists of modes 2 and 7 in their untransposed forms, and modes 1, 4, and 6 transposed up a perfect 
fourth. It should be noted, however, that the closest Euclidean distance between modes 1 and 4 involves no transposition.

\section{Multidimensional Scaling}

To investigate more thoroughly the apparent supramodal groupings suggested above, we turn to multidimensional scaling, a useful quantitative method for illustrating similarity relationships (Kruskal \& Wish, 1977). Multidimensional scaling, or MDS, is an analytical method that produces a geometric picture from distance-like data. In psychometric applications, these distance-related data usually represent some measure of similarity. For the benefit of readers unfamiliar with the MDS method, a brief description is appropriate.

The input to MDS is a set of distance measures between objects. The procedure endeavors to fit these objects in an $n$-dimensional space so that the measured distances between objects are preserved as closely as possible. For example, given the travel times between various European cities, the method can be used to generate a map showing the geometrical relationship between the cities. The number of dimensions in the generated picture depends on the nature of the data and the amount of "stress" the procedure exerts by shifting the data-points slightly so all points are represented. For example, if we provided an MDS procedure with the travel times between major cities from around the world, a two-dimensional solution would not be possible without considerable stress, whereas a three-dimensional solution (allowing the representation of the spherical earth) would have a much lower stress. While MDS can produce several dimensions in the output, the method provides no interpretation of the meaning of the dimensions. In the case of a physical map, for example, one dimension might represent a north-south axis, but this interpretation is the prerogative of the researcher, not the MDS method.

In the present study, we provided the MDS procedure with a set of 28 distances representing the similarity between all possible pairings of eight modes. Similarity measures were calculated as Euclidean distances between the pitch-class-proportion vectors in the 12-dimensional space as already described. Once again transpositions must be considered. In order for the MDS output to give a consistent geometry, a fixed transpositional relationship must be established between all of the modes. One way to establish this relationship is to calculate the aggregate Euclidean distances between all modes for a particular arrangement of transpositions. Transpositional arrangements were systematically investigated until the smallest average distance was determined. The least aggregate distance was evident when modes 2 and 7 were both transposed up a perfect fourth with all other modes remaining untransposed. This arrangement is consistent with our previous analysis.

A two-dimensional MDS solution for these measures is shown in Figure 4 (stress $=0.0817$ using Kruskal's stress formula $1 ; R^{2}=0.968$ ). Once again, the MDS solution is consistent with a broad distinction between at least two groups. Specifically, modes 3, 5, and 8 are well segregated from the other modes along dimension 1 .

\section{Cluster Analysis of Individual Works}

The preceding analyses were carried out using aggregate mode profiles. That is, each mode profile was the result of amalgamating a number of individual chants presumed to be in the same mode. In amalgamating these chants, we have assumed that the mode designations provided by the monks of Solesmes are correct and reflect an underlying natural organization. A maximally contrasting analysis might reject this assumption and seek to characterize the groupings of individual chants without regard to an a priori classification scheme. If it is indeed the case that modes 3,5 , and 8 are highly similar, then a strong grouping tendency should be evident in the mode profiles for individual chants.

A useful technique for bottom-up grouping is provided by cluster analysis (Duran \& Odell, 1974). Cluster analysis is a statistical technique that groups objects according to their parametric similarity. The two most similar objects are grouped together first. As the clustering continues, groups of groups are formed until the entire set of objects is rendered as a single large group. For this analysis, each individual chant was characterized according to the distribution of untransposed pitch classes within the chant. Since we are presuming to have no knowledge of the actual mode for individual chants, this analysis must be carried out without transpositions (since we cannot presume to know how the modes ought to be transposed 


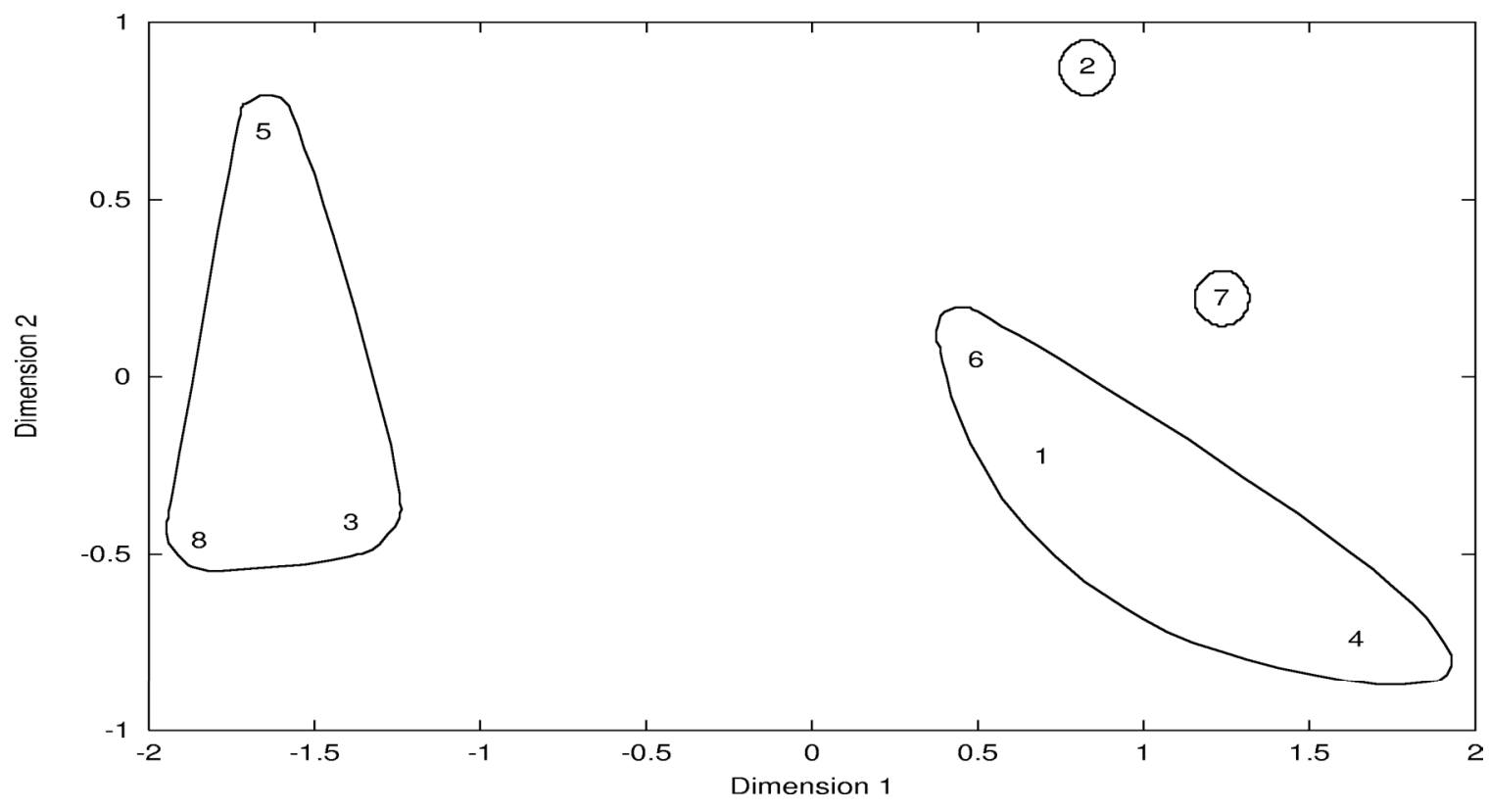

Figure 4. Graphic representation of a multidimensional scaling (MDS) solution where the vectordifferences have been measured between optimally transposed pitch-class distributions (mode profiles). Circled groups represent the classification proposed by the 11 th-century theorist, Johannes Cotto. The stress for this two-dimension solution was determined to be 0.0817 using Kruskal's stress formula $1\left(R^{2}=0.968\right)$. Dimensions 1 and 2 are drawn to scale making it easier to see that Dimension 1 accounts for a greater proportion of the variance. The modes 3,5 and 8 all share the pitch $\mathrm{C}$ as the tenor, and all appear on the left side of dimension 1 . The modes 1,4 and 6 have $\mathrm{A}$ as the tenor, and all appear on the right side of dimension 1. Note the large empty region separating the 3-5-8 mode group from the remaining modes. Dimension 1 suggests a nascent major/minor bifurcation. The graph should not be construed as evidence that medieval listeners were unable to distinguish each of the eight modes. Although the musical practice represented in the sampled music pre-dates the emergence of major/minor tonality, the results suggest that the possibility for confusion between the modes is already evident in medieval music, and that the preeminent polarity of confusion is consistent with the major/minor distinction.

with respect to one another). The use of untransposed data means that the likelihood of observing true supramodal groups is diminished. However, the use of untransposed data does not increase the likelihood that those groups that emerge from the analysis are spurious. That is, although chants characterized as dissimilar according to the cluster analysis may in fact be similar, chants that are judged similar according to the cluster analysis are unlikely to be actually dissimilar.

The chants were clustered according to the similarities of their individual pitch class profiles. The results are displayed in the tree diagram shown in Figure 5. The "leaves" of the tree indicate individual chants. For comparison purposes, numbers are provided showing the actual Solesmes mode designations. In addition, the tenor pitches are indicated in accordance with Johannes Cotto's claim concerning the importance of the tenor in modal classification. Recall that the tenor for modes 3,5 and 8 is $\mathrm{C}$; the tenor for modes 1,4 and 6 is $\mathrm{A}$; the tenor for mode 2 is $\mathrm{F}$; and the tenor for mode 7 is $\mathrm{D}$.

Most noteworthy is the preponderance of chants with $\mathrm{C}$ tenors in the right-most half of the highest-level two-part division. Of the 38 chants in right-most cluster, 27 carry mode designations of 3,5 , or 8 . Dropping down to the fourth highest level, the right-most cluster (marked *) shows that 27 of 31 are designated as modes 3,5 , or 8 with $\mathrm{C}$ tenors. By contrast, only five chants in modes 3 , 5, or 8 can be found in the left region clusters.

Conversely, the left-hand division shows a preponderance of chants with A tenors (modes 1, 4 and 6). Chants with $\mathrm{F}$ tenors (mode 2) tend to appear in a cluster in the center of the diagram. No single cluster seems to correspond to D tenors (mode 7). 




Figure 5. Cluster analysis of pitch-class profiles for 98 randomly selected chants from the Liber usualis. Numbers indicate the mode as designated in that source. Letters indicate the tenor pitches for each chant. Most noteworthy is the preponderance of chants with $\mathrm{C}$ tenors in the rightmost half of the highest-level two-part division. In general, the cluster analysis implies that modes 3,5 and 8 tend to group together-a tendency also observed for the aggregate profile data. 
In general, the cluster analysis implies that the 3-5-8 grouping observed for the aggregate profile data is also apparent in the profiles of individual chants. It bears emphasizing that the same data was used in both the aggregate profile analysis and the cluster analysis, so it should not be surprising that the results are consistent. The cluster analysis merely demonstrates that the patterns evident in the aggregate profile data are also evident in the profiles for the individual chants themselves.

\section{Converging Evidence of Similarity: Phrase Endings}

The structural tonality view suggests that the tonic is not only likely to be among the most frequently occurring pitch class, but also that this tone is likely to be heard as the most stable. Since musical works typically end with a sense of closure, these stable pitches often predominate in terminating positions. As noted earlier, this pattern has been observed in both Western and non-Western musics. Of course, in the case of modes, different classifications are assigned to chants ending on different pitches. By definition, modes 3,5 and 8 (for example) will end on different pitches. However, if they share some sort of commonality with respect to the relative stability of the various scale tones, these ought to be evident at phrase endings (i.e., "medials").

To this end, we extracted the phrase-terminating pitches from our mode samples. In the Liber usualis, phrases are marked by divisiones (divisions: vertical lines of varying heights). Table 8 provides tallies of the number of occurrences where different pitch classes appear at phrase endings. Since the finalis tones were used by the monks of Solesmes to help classify the modes, the finalis tones have been omitted in these tallies.

$\begin{array}{lcccccccc} & \text { Mode 1 } & \text { Mode 2 } & \text { Mode 3 } & \text { Mode 4 } & \text { Mode 5 } & \text { Mode 6 } & \text { Mode 7 } & \text { Mode 8 } \\ \text { A } & 26 & 37 & 8 & 14 & 30 & 4 & 7 & 13 \\ \text { B-flat } & 0 & 0 & 0 & 0 & 1 & 1 & 0 & 0 \\ \text { B } & 0 & 2 & 9 & 0 & 0 & 2 & 8 & 1 \\ \text { C } & 13 & 17 & 8 & 7 & 22 & 15 & 7 & 7 \\ \text { D } & 32 & 27 & 7 & 17 & 1 & 9 & 30 & 2 \\ \text { E } & 1 & 8 & 11 & 35 & 0 & 2 & 1 & 0 \\ \text { F } & 16 & 7 & 8 & 16 & 23 & 34 & 6 & 13 \\ \text { G } & 12 & 10 & 30 & 18 & 12 & 18 & 28 & 49\end{array}$

Table 8. Tally of Pitch Classes for Medial Cadences According to Mode

Calculating the correlations between the untransposed distributions, the highest correlation is between modes 3 . and $8(r=+0.92)$. Contrary to our previous analyses, there is no evidence for any similarity between medials for modes 3 and $5(r=-0.09)$. Although there appears to be a slight similarity between the medials for modes 5 and 8 , this is not statistically significant. On the other hand, the high correlation between modes 3 and 8 suggests that modes 3 and 8 differ little, except for the finalis tones.

\section{ASSUMPTIONS AND CAVEATS}

The results of this study can be properly interpreted only in light of the many assumptions, limitations, and caveats that attend the methods used. In the first instance, the sampled chant materials used in this study all originate in a single source, the Liber usualis. While this source is considered to be one of the most scholarly, like all modem editions, this volume is a reconstruction and interpretation of various earlier sources, and the processes of selection, interpretation, and editing may introduce unknown biases. Our musical sample contains no secular works and so is biased toward sacred repertory. The chants represented in the Liber usualis arose over the course of several centuries. These materials have been collapsed into a single sample without regard to historical period. Consequently, any period-related differences in modal practice will fail to be evident in the results. Moreover, the combining of different periods of modal practice might lead to results that are representative of no actual period and so portray an average practice that never ex- 
isted. The Liber usualis includes a wide variety of chant genres. No effort was made to determine whether particular modes tend to favor certain genres, so possible genre/mode interactions have been ignored. Finally, with the exception of the cluster analysis, the mode designations provided by the monks of Solesmes were accepted as correct classifications.

Apart from the sample of music used, other assumptions and limitations are evident in the perceptual model underlying the analyses. While we have made no claims here about how medieval listeners actually perceived the various modes, we have assumed that medieval listeners are similar to modem listeners in being sensitive to the frequency of occurrence of various pitches. This assumption would seem warranted given the experimental literature on statistical learning in audition for both adults and infants (e.g., Saffran, Johnson, Aslin \& Newport, 1999), as well as cross-cultural evidence. However, it bears noting that these notions are based on experimental work with only a small number of listeners from three different cultures (Balinese, North Indian, Western) and the analysis of music in a fourth culture (Korean). Our approach was motivated by a modem understanding of structural tonality with only secondary regard for theoretical notions contemporaneous with the music itself.

Finally, the current study is limited by the types of analyses carried out. Since no perceptual experimentation is possible, all analyses carried out were correlational in nature, with all the limitations that attend such methods. In addition, in this study we have not examined the presence of melodic archetypes (which are thought by chant scholars to be important in modal characterization). Moreover, this study did not analyze interval relationships that might provide a better way of classifying modes.

\section{CONCLUSION}

With these limitations as background, the current study suggests the following:

1. The frequency of occurrence of pitches in a chant is broadly predictive of the chant's mode as conventionally designated.

2. A possible exception to this pattern is evident in modes 3 and 8 (Lydian and Hypomixolydian) which are easily confused when characterized according to pitch-class distributions.

3. When the Euclidean distance is measured between the aggregate pitch-class distributions for the eight modes, modes 3, 5 and 8 are close neighbors. (Note that the test chants for modes 3,5 and 8 shown in Table 5 were all classified as D Hypomixolydian. If modes 3,5 and 8 are regarded as the same mode, then the classification accuracy reported in Table 5 increases from 6/16 to 10/16.) Similarly, modes 1, 4, and 6 form a (less tightly organized) group. Mode 2 (Hypodorian) appears to be isolated from the other modes. Chants designated mode 7 (Mixolydian) are highly varied and so it is difficult to relate this mode to the others.

4. This pattern of similarities is strikingly reminiscent of the description of modal categories offered by the 11th-century theorist, Johannes Cotto. He argued that modes are usefully characterized by their tenors (one of the more frequently repeated pitches). Modes 3, 5 and 8 all share $\mathrm{C}$ as the tenor; modes 1, 4 and 6 share $\mathrm{A}$ as the tenor; modes 2 and 7 have F and D tenors respectively.

5. Comparing all pairs of modes through all possible transpositions provided measures of the Euclidean distances between the relative pitch-class distributions. Using the transpositional arrangement with the lowest aggregate distances, the Euclidean distances were measured between all mode combinations. This procedure allowed us to generate a multi-dimensional scaling (MDS) solution. A two-dimensional solution accounted for $97 \%$ of the variance, and the placement of the modes resembled the classification advocated by Johannes Cotto. One dimension in particular accounted for the bulk of the variance in the differences between the relative pitch-class distributions. This dimension separates all modes with $\mathrm{C}$ tenors from all other modes.

6. A cluster analysis of the distributions of the individual chants also shows a strong tendency to distinguish modes 3,5 and 8 from all other modes. Chants designated mode 7 showed little tendency to cluster together.

7. Modes 3,5 and 8 differ in the final tones. However, an analysis of the pitches which end nonterminating phrases (medial cadences) shows a strong positive correlation between modes 3 and 8 . Little correlation was evident between the medial cadences for mode 5 and either modes 3 or 8 . From the point of view of structural tonality, modes 3 and 8 (Phrygian and Hypomixolydian) are the most similar of the modes. 


\section{DISCUSSION}

In the context of debates concerning the emergence of the major/minor system in Western music, the above results are suggestive. In the 16th century, Henricus Glareanus argued that the existing eight-mode system should be theoretically expanded by adding plagal and authentic forms using C (Ionian) and A (Aeolian) as finals. Glareanus' proposed expansion was echoed by the famous 16th-century theorist Gioseffo Zarlino and was taken up by a number of composers, including Claude Le Jeune and Giovanni Gabrieli. Music scholars have widely regarded this expansion of the eight-fold modal system to a twelve-fold system as a crucial step toward the emergence of the major/minor system of tonality.

The results in this study do not contradict such an interpretation. However, they also suggest that the groundwork for the emergence of the major/minor system may have been amply prepared in earlier centuries. As we have seen, the principal dimension in our MDS analysis implies a "major/minor"-like interpretation. From the point of view of structural tonality, the most similar modes $(3,5$, and 8$)$ all employ $\mathrm{C}$ as the principal reciting tone or tenor. A second (though more diverse) group consists of modes 1, 4 and 6 (Dorian, Hypophrygian, and Hypolydian) which all share A as the reciting tone or tenor. The MDS plot seems to provide support for Johannes Cotto's view that mode 2 (Hypodorian) is somewhat unique. The MDS analysis is less consistent with Cotto's view of the uniqueness of mode 7 (Mixolydian). The cluster analysis suggests that mode 7 lacks a unifying characteristic, at least with respect to the distribution of pitch classes.

If we accept at face value Cotto's claim that the modes distill into four groups, it remains the case that two of these groups (3-5-8 and 1-4-6) predominate. One could well imagine that although the Ionian and Aeolian modes were introduced for largely theoretical reasons, the introduction of additional modes that emphasize the pitches $\mathrm{C}$ and $\mathrm{A}$ would further cement the polarity of an existing 3-5-8 and 1-4-6 modal grouping. It is plausible that the plagal and authentic Ionian modes would cohere perceptually with 3-5-8, while the plagal and authentic Aeolian modes would cohere perceptually with the 1-4-6 group.

This sort of merging of perceptual schemas is well established in the field of historical linguistics. Linguists have shown that it is commonplace for two previously distinguished phonemes to lose their distinctiveness in some language and, over time, to join to form a single phoneme category. For example, all English speakers used to distinguish between the "ah" sounds found in the words "caught" and "cotton." This distinction is retained by speakers in New York and New England, but most speakers of American English no longer make this distinction. Linguists call this process merger (e.g., Katamba, 1989).

One might posit a similar process in the case of modal schemas. The movement to the twelve-fold system of modes might well have been the precipitating event that caused the modal system to collapse into two rather broad categories. Listeners would simply find it too difficult to maintain separate pitch-class schemas for all the different modes, and would tend to confuse those modes which exhibit the most similar pitch-class profiles.

This study has shown that groups of similar mode profiles existed hundreds of years before Glareanus proposed adding the Ionian and Aeolian modes. The implication is that medieval listeners might have already experienced some difficulty in discriminating all eight modes-setting the stage for modal merger.[8]

\section{NOTES}

[1] No short list of citations could do justice to the volume and breadth of writings on this subject. This list is intended to be illustrative rather than exhaustive.

[2] To avoid possible confusion, non-chant scholars should be aware that the term "psalm tone" refers to a melodic formula, and does not refer to an individual pitch.

[3] As noted, historical sources for the same chant can differ when identifying the mode of the work. Such conflicting mode assignments might provide useful independent evidence for characterizing the relative similarity of certain groups of modes.

[4] We will delay presenting these mode profiles (shown in Figure 3) until after a test of their predictive efficacy using an independent sample. If the test proves successful, then the profiles can be presented as an aggregate of all the available data. 
[5] This sampling criterion had the unanticipated side effect of selecting certain chant types and not others, leading to a preponderance of more ornate, responsorial types such as Graduals.

[6] The problem with the use of correlation was observed by von Hippel and Huron (2000) in applying the Krumhansl and Schmuckler key-finding algorithm to twelve-tone music. By way of illustration, consider the case of a single pitch (say, C) that is repeated 50 times. This passage will exhibit a correlation of +0.68 with the Krumhansl and Kessler C major key profile. Now consider a twelve-tone work in which each pitch class occurs with nearly identical frequency. For example, each pitch class (except C) occurs 200 times; the pitch $\mathrm{C}$, however, occurs 201 times. Calculating a correlation eliminates offset values, so this passage will also exhibit a correlation of +0.68 with the key of $\mathrm{C}$ major. (Moreover, the correlation between the repeated tone passage and the twelve-tone work will be a disturbingly perfect +1.00 .) A better approach to measuring similarity would take into account the actual proportions for each pitch class.

[7] The calculation can be demonstrated by considering an illustration where only three pitch classes are possible and two hypothetical modes exhibit the following proportions of the three pitch classes: $50 \%$, $20 \%, 30 \%$ and $40 \%, 30 \%, 30 \%$. The Euclidean distance can be calculated as the sum of the square roots of the sum of the squares. This is exactly analogous to determining the length of the diagonal between two points in a three dimensional space whose positions are $(40,30,30)$ and $(50,20,30)$.

$$
\begin{array}{ll}
\text { I.e., } & \sqrt{(.50-.40)^{2}+(.20-.30)^{2}+(.30-.30)^{2}} / 10=\sqrt{0.1^{2}+0.1^{2}+0} / 10=\sqrt{100+100} / 10= \\
& 14.1421 / 10=0.141421
\end{array}
$$

[8] The authors are grateful to Bret Aarden for carrying out the MDS and clustering analyses.

\section{REFERENCES}

Aarden, B. (2003). Dynamic Melodic Expectancy. Ph.D. dissertation, School of Music, Ohio State University.

Apel, W. (1958). Gregorian Chant. Bloomington: Indiana University Press.

Atkinson, C.M. (1982). “The Parapteres: Nothi or Not?” Musical Quarterly, Vol. 68, pp. 32-59.

Atkinson, C.M. (1989). On the interpretation of 'modi, quos abusive tonos dicimus.' In: Hermeneutics and Medieval Culture. Albany: State University of New York, pp. 147-161.

Atkinson, C.M. (1995). “Modus.” In: Handwörterbuch der Musikalischen Terminologie. Wiesbaden: F. Steiner.

Auda, A. (1979). Les modes et les tons de la musique et specialement de la musique medievale. Hildesheim: Olms.

The Benedictines of Solesmes (Eds.) (1961). The Liber Usualis with Introduction and Rubrics in English. Tournai: Desclee Company.

Butler, D. (1999). Tonal bootstrapping: Re-thinking the intervallic rivalry model. In: Suk Won Yi (Ed.), Music, Mind, and Science. Seoul: Seoul National University Press, pp. 7-12.

Brown, H. (1988). The interplay of set content and temporal context in a functional theory of tonality perception. Music Perception, Vol. 5, No. 3, pp. 219-250.

Butler, B. \& Brown, H. (1981). Diatonic trichords as minimal tonal cue-cells. In Theory Only, Vol. 5, pp. 39-55. 
Castellano, M., Bharucha, J., \& Krumhansl, C. (1984). Tonal hierarchies in the music of North India. Journal of Experimental Psychology: General, Vol. 113, pp. 394-412.

Cotto, Johannes (n.d.). De musica. (11th century). Available as: J. Smits van Waesberghe (Ed.). (1950). Corpus scriptorum de musica. Rome: American Institute of Musicology. English trans.: Warren Babb. Claude Palisca (Ed.). (1978). Hucbald, Guido, and John on Music: Three Medieval Treatises. New Haven: Yale University Press.

Cuddy, L. (1993). Melody comprehension and tonal structure. In: T. Tighe \& W.J. Dowling (Eds.). Psychology and Music: The Understanding of Melody and Rhythm. New Jersey: Erlbaum, pp. 19-38.

Cuddy, L. \& Baderstscher, B. (1987). Recovery of the tonal hierarchy: Some comparisons across age and levels of musical experience. Perception \& Psychophysics, Vol. 41, No. 6, pp. 609-620.

Cuddy, L. (1997). Tonal relations. In: I. Deliège \& J. Sloboda (Eds.). Perception and Cognition of Music. Hove, East Sussex: Psychology Press, pp. 329-352.

Curtis, L. (1992). “Mode.” In: Companion to Medieval and Renaissance Music. London: Dent, pp. 255264.

Duran, B.S. \& Odell, P.L. (1974). Cluster Analysis. New York: Springer-Verlag.

Glareanus, Henricus. (1547). Dodecachordon. Basel: [no pub.]. Available in facsimile: (1967). New York: Broude Brothers. English trans.: C.A. Miller. (1965). Musicological Studies and Documents, Vol. 6. [no place]: American Institute of Musicology.

Gombosi, O. (1938-40). Studien zur Tonartenlehre des frühen Mittelalters. Acta musicologica, Vol. 10 (1938), pp. 149-174; Vol. 11 (1939), pp. 28-39, 128-135; Vol. 12 (1940), pp. 21-52.

Hebert, S., Peretz, I. \& Gagnon, L. (1995). Perceiving the tonal ending of tune excerpts: The roles of preexisting representation and musical expertise. Canadian Journal of Experimental Psychology, Vol. 49, No. 2, pp. 193-209.

von Hippel, P. \& Huron, D. (2000). Tonal and contra-tonal structure of Viennese twelve tone rows. Paper presented at the Society for Music Theory Conference. Toronto, Canada.

Hucke, H. (1974). Die Herkunft der Kirchentonarten und die fränkische Überlieferung des gregorianischen Gesangs. Berlin: Gesellschaft für Musikforschung: Kongress-Bericht, pp. 257-60.

Huron, D. (1988). Error categories, detection and reduction in a musical database. Computers and the Humanities, Vol. 22, No. 4, pp. 253-264.

Huron, D. (1999). Music Research Using Humdrum: A User's Guide. Stanford, California: Center for Computer Assisted Research in the Humanities.

Huron, D. \&. Parncutt, R. (1993). An improved model of tonality perception incorporating pitch salience and echoic memory. Psychomusicology, Vol. 12, pp. 154-171.

Katamba, F. (1989). An Introduction to Phonology. London: Longman.

Kessler, E.J., Hansen, C. \& Shepard, R. (1984). Tonal schemata in the perception of music in Bali and the West. Music Perception, Vol. 2, pp. 131-165.

Krumhansl, C. (1990). Cognitive Foundations of Musical Pitch. Oxford: Oxford University Press. 
Krumhansl, C. \& Kessler, E.J. (1982). Tracing the dynamic changes in perceived tonal organization in a spatial representation of musical keys. Psychological Review, Vol. 89, pp. 334-368.

Kruskal, J.B. \& Wish, M. (1977). Multidimensional Scaling. Beverly Hills: Sage Publications.

Lamont, A. (1998). Music, education, and the development of pitch perception: The role of context, age, and musical experience. Psychology of Music, Vol. 26, pp. 7-25.

Lantz, M.E. \& Cuddy, L.L. (1998). Total and relative duration as cues to surface structure in music. Canadian Acoustics, Vol. 26, No. 3, pp. 56-57.

Maitre, C. (1997). La modalité du plain-chant au Moyen age. Musurgia: Analyse et pratique musicales, Vol. 4, No. 3, pp. 31-42.

Markovits, M. (1977). Das Tonsystem der abendländischen Musik im frühen Mittelalter. Bern: Paul Haupt.

Nam, U. (1998). Pitch distributions in Korean court music: Evidence consistent with tonal hierarchies. Music Perception, Vol. 16, No. 2, pp. 243-247.

Oram, N. \& Cuddy, L.L. (1995). Responsiveness of Western adults to pitch distributional information in melodic sequences. Psychological Research/Psychologische Forschung, Vol. 57, No. 103-118.

Potiron, H. (1953). La composition des modes gregoriens. Tournai: Desclee.

Powers, H.S. (1992). Modality as a European cultural construct. In: Rossana Dalmonte and Mario Baroni (Eds.). Secondo Convegno Europeo di Analisi Musicale. Trent, Italy: U. degli Studi di Trento.

Powers, H.S. / Wiering, F. (2001). Mode: II. Medieval modal theory. Stanley Sadie (Ed.). The New Grove Dictionary of Music and Musicians, 2nd ed. New York: Grove.

Saffran, J.R, Johnson, E.K., Aslin, RN. \& Newport, E.L. (1999). Statistical learning of tone sequences by human infants and adults. Cognition, Vol. 70, pp. 27-52.

Schlager, K. (1985). Regionaltradition und Modalität in der liturgischen Monodie des Mittelalters. Studia musicologica Academiae Scientarum Hungaricae, Hungary, Vol. 27, Nos. 1-4, pp. 117-122.

Shepard, R.N. (1962). The analysis of proximities: Multidimensional scaling with an unknown distance function. I \& II. Psychometrika, Vol. 27, pp. 125-140, 219-246.

Torgeson, W.S. (1951). Multidimensional scaling: I. Theory and method. Psychometrika, Vol. 17, pp. 401-419.

West, R. \& Fryer, R. (1990). Ratings of suitability of probe tones as tones after random orderings of notes in the diatonic scale. Music Perception, Vol. 7, No. 3, pp. 253-258.

\section{APPENDIX}

Chants used in this study (the 16 test chants are marked by an asterisk):

\section{Title}

Amen dico vobis

Assumpsit Jesus Petrum

Beata nobis gaudia

Concupivit rex

$\begin{array}{cc}\text { Mode } & \text { Page No. in Liber usualis } \\ 1 & 1206 \\ 1 & 1588-89 \\ 1 & 876 \\ 1 & 1230\end{array}$


Cum immundus spiritus

Domine, quinque

Exsurge, quare obdormis Domine?

Hodie egressa est

Iste Confessor Domini

1321-22

Misso Herodes spiculatore

1198

Principes sacerdotum

1618

Vocabis nomen

1101

Gloriosus Deus*

453

1163

In conspectu*

1546

A fructu frumenti

923

Alleluia V/. Redemptionem misit Dominus

822

Beata Dei Genitrix

260

Hodie scietis

Magnum haereditatis mysterium

360-61

444

Meditabor in mandatis

548-49

O Clavis David

341

Obtulerunt pro Domino

1360-61

Ut queant laxis

A summo caelo*

1504

Angelis suis mandavit*

$343-44$

533

Elisabeth Zachariae

1503

Exsurge Domine

553-54

Filiae regum

Omnia quae fecisti

1228

1063

Petrus quidem servabatur

1577

Placebo Domino

Sancti tui, Domine

1772

Sapientia reddidit

1149-50

1440

Simeon justus

1366

Vota mea

281

Alleluia V/. Cognoverunt*

$817-18$

382

1675

Ascendit Deus

1380

Candor est lucis

1522

Decora lux

767-68

Et ecce apparuerunt

Jam toto subitus

Justitiae Domini

$\mathrm{Ne}$ reminiscaris

Perfice gressus meus

Propheta magnus

1589

1640

$555-56$

992

508

1096

Quem vidistis, pastores?

$377-78$

Salus populi

Sitivit anima mea

1059-60

450

Turba multa

585

Illumina oculos meos*

1000-01

Tenuisti manum*

593-94 
Benedicamus Domino

Justus cum ceciderit

Plange quasi virgo

Probasti, Domine

761

Quemadmodum desiderat

594-95

Solvite templum hoc

Tribulationes cordis mei

1478-79

1094

546-47

910

Gloria et honore*

1133-34

Ave Regina caelorum

278

De fructum operum tuorum

1031-32

Dicit Dominus

Ego sum Gabriel

Fecit Joas

Gaudent in caelis

In sermonibus Domini

In virtute tua

Posuisti Domine

487-88

1408

988-989

1160-61

1681.1

1205-06

Serve nequam

1135

1070

Tu es Petrus

1521

Ubi caritas

Domine, in auxilium*

675

1046

Sanctus*

38-9

Alleluia V/. Te decet hymnus

1022

Alleluia V/. Jesus autem

1283B

Clamaverunt justi

1170-71

Factus est repente

1281

Liberavit Dominus

Magnificatibur

638

1706

Misereor super turbam

1009

Populus Sion

$327-28$

Veni Domine visitare

327

Circumduxit eam*

1671

Eram quasi agnus*

649-50

Alleluia V/. Haec dies

805

Amicus meus

643-44

Iste Sanctus

1123

Lucis Creator optime

256

Magister, scimus quia

1107

Paraclitus autem

Qui regis Israel

900

351

Te lucis ante terminum

266-67

Viam mandatorum

1474

Alleluia V/. Vos estis*

1548

Vinea mea*

$697-98$ 